\title{
Estimating Resting Core Temperature Using Heart Rate
}

\author{
David P. Looney \\ U.S. Army Research Institute of Environmental Medicine and Oak Ridge Institute for Science and Education (ORISE)
}

\author{
Mark J. Buller \\ U.S. Army Research Institute of Environmental Medicine
}

Andrei V. Gribok and Jayme L. Leger

United States Department of Agriculture

Adam W. Potter

U.S. Army Research Institute of Environmental Medicine

William V. Rumpler

United States Department of Agriculture

\section{William J. Tharion, Alexander P. Welles, Karl E. Friedl, and Reed W. Hoyt \\ U.S. Army Research Institute of Environmental Medicine}

\begin{abstract}
ECTemp $^{\text {TM }}$ is a heart rate (HR)-based core temperature (CT) estimation algorithm mainly used as a real-time thermal-work strain indicator in military populations. ECTemp ${ }^{\mathrm{TM}}$ may also be valuable for resting CT estimation, which is critical for circadian rhythm research. This investigation developed and incorporated a sigmoid equation into ECTemp ${ }^{\text {TM }}$ to better estimate resting CT. HR and CT data were collected over two calorimeter test trials from 16 volunteers (age, $23 \pm 3$ yrs; height, $1.72 \pm 0.07 \mathrm{~m}$; body mass, $68.5 \pm 8.1 \mathrm{~kg}$ ) during periods of sleep and inactivity. Half of the test trials were combined with ECTemp $^{\text {тм, }}$ s original development dataset to train the new sigmoid model while the other was used for model validation. Models were compared by their estimation accuracy and precision. While both models produced accurate CT estimates, the sigmoid model had a smaller bias $\left(-0.04 \pm 0.26^{\circ} \mathrm{C}\right.$ vs. $\left.-0.19 \pm 0.29^{\circ} \mathrm{C}\right)$ and root mean square error $\left(\mathrm{RMSE} ; 0.26^{\circ} \mathrm{C}\right.$ vs. $\left.0.35^{\circ} \mathrm{C}\right)$. ECTemp $^{\text {TM }}$ is a validated HR-based resting CT estimation algorithm. The new sigmoid equation corrects lower CT estimates while producing nearly identical estimates to the original quadratic equation at higher CT. The demonstrated accuracy of ECTemp $^{\text {TM }}$ encourages future research to explore the algorithm's potential as a non-invasive means of tracking CT circadian rhythms.
\end{abstract}

Keywords: circadian rhythm, core body temperature, extended kalman filter

\begin{abstract}
(c) 2018 The Authors. Published by Human Kinetics, Inc. This is an Open Access article distributed under the terms of the Creative Commons Attribution License CC BY NC 4.0, which permits unrestricted noncommercial use, distribution, and reproduction in any medium, provided the original work is properly cited, the new use includes a link to the license, and any changes are indicated. See http:// creativecommons.org/licenses/by-nc/4.0. This license does not cover any third-party material which may appear with permission in the article. For commercial use, permission should be requested from Human Kinetics, Inc., through the Copyright Clearance Center (http://www.copyright.com).
\end{abstract}

Looney, Buller, Potter, Tharion, Welles, and Hoyt are with the Biomedical and Biophysical Modeling Division, U.S. Army Research Institute of Environmental Medicine, Natick, MA. Gribok, Leger, and Rumpler are with the Components and Health Laboratory, Beltsville Human Nutrition Research Center, Agricultural Research Service, United States Dept. of Agriculture, Beltsville, MD. Looney is also with the Oak Ridge Institute for Science and Education (ORISE), Oak Ridge, TN. Friedl is with the Science Management Office, U.S. Army Research Institute of Environmental Medicine, Natick, MA. Potter (adam.w.potter.civ@mail.mil) is corresponding author.
In healthcare and in general living conditions body core temperature (CT) is considered one of the most informative indicators of thermal stress (Montain, Sawka, Cadarette, Quigley, \& McKay, 1994; Sawka et al., 2001), a key indicator in thermal comfort (Gagge et al., 1967), and has a wide range of clinical and diagnostic values. Clinical definitions use two key inputs for diagnoses, CT and observable neurological (dis)function; where heat exhaustion $\mathrm{CT}$ is between $37-40^{\circ} \mathrm{C}$ and heat stroke is above $40^{\circ} \mathrm{C}$ when paired with central nervous system dysfunction or irregularities (Bouchama \& Knochel, 2002). Core temperature has also been long used to provide indications of early warning onset of infections (e.g., fever onset). Given the importance of $\mathrm{CT}$ as an indicator of thermal stress, thermal comfort level, and health status, the ability to reliably monitor, measure, estimate, and predict CT and rise in CT over time has been and continues to be a keen interest within the research and clinical communities. 
Given the stable settings of traditional clinical care facilities, the ability to monitor core body temperature clinically has long been achievable (e.g., via stable rectal thermometry); while the ability to monitor and measure CT in free-roaming environments has only recently been achievable. From early uses in research settings or similar to demands of astronauts, rectal probes have long been used as a means of monitoring rectal temperature as a measure of CT. However, for an array of reasons (e.g., comfort, reliability) the use of rectal probes needed improving (Poole \& Stephenson, 1977). Advances in micro-electronics enabled the development of ingestible temperature sensing via a pill that telemeters data of continuous measures from a near-infrared measure from the location (swallowed or placed rectally) (O'Brien, Hoyt, Buller, Castellani, \& Young, 1998). Improvements to these pills have been made continuously (Hunt, Bach, Borg, Costello, \& Stewart, 2017) and these telemetry-based pills are a great improvement over the use of rectal probes (less invasive, easier to use, fairly scalable).

A number of methods have been developed over the years to predict CT from less invasive measures (e.g., heart rate, skin temperature, respiration rate) (Buller et al., 2013; Niedermann et al., 2014; Richmond, Davey, Griggs, \& Havenith, 2015) as well as methods to predict CT from estimations, approximations, or actual measures of environmental conditions, clothing, activity, and individual parameters (Potter, Blanchard, Friedl, Cadarette, \& Hoyt, 2017). The approaches by both Niedermann et al. (2014) and Richmond et al. (2015) both initially collected a range of measurements and narrowed them down to fewer in order to obtain reasonable estimates of $\mathrm{CT}$ while being near- non-invasive. While both approaches use non-invasive measures (e.g., skin temperature, heat flux, heart rate); less involved methods of sensing are more ideal (e.g., single measure / sensor) such as solely heart rate (Buller et al., 2013).

While the majority of estimation methods for CT have focused on stressed environments during exercise conditions, resting CT modeling is particularly valuable for research and clinical purposes including circadian rhythm monitoring. Circadian rhythm research has grown considerably over the past two decades (Refinetti, Lissen, \& Halberg, 2007) as circadian disturbances have been linked to cancer (Savvidis \& Koutsilieris, 2012), neuropsychiatric illness (Jagannath, Peirson, \& Foster, 2013), and obesity (Shi, Ansari, McGuinness, Wasserman, \& Johnson, 2013). However, implementing traditional CT measurement techniques in freeliving settings is difficult. A need exists for an accurate resting CT estimator compatible with free-living settings.

Heart rate (HR)-based CT estimation models have been used to estimate resting CT and circadian rhythms under free-living conditions (Sim et al., 2016). ECTemp ${ }^{\text {TM }}$ is a HR-based core temperature (CT) estimation algorithm used mainly as a realtime thermal strain indicator in military populations (Buller et al., 2013; Buller, Tharion, Duhamel, \& Yokota, 2015). ECTemp $^{\text {TM }}$ demonstrated high accuracy and precision (bias, $-0.03 \pm$ $0.32^{\circ} \mathrm{C}$ ) when validated on over 52,000 observations from 83 volunteers from 9 different studies that involved intense, strenuous activity and heat stress (Buller et al., 2013).

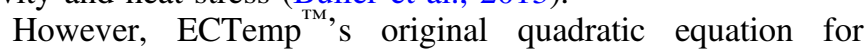
describing the gradual saturation in HR at higher CT may not adequately model the CT-HR relationship at lower CT (Looney et al., 2017). The quadratic equation does not predict CT under $36^{\circ} \mathrm{C}$ unless $\mathrm{HR}$ drops below physiological limits $(<27 \mathrm{bpm})$. The original development dataset contained few data points at lower CT to maximize CT estimation accuracy during high thermal-work strain (Tharion et al., 2013). ECTemp ${ }^{\mathrm{TM}}$ must be adapted to accurately estimate lower CT before it can be examined as a potential CT circadian rhythm estimator.

Retraining ECTemp ${ }^{\mathrm{TM}}$ with additional resting CT data may increase accuracy and precision of lower CT estimates. We hypothesized that a sigmoid equation would better characterize the saturation in HR at both upper and lower CT compared the original quadratic equation. The purpose of this investigation was to develop and validate a new sigmoid equation for ECTemp ${ }^{\mathrm{TM}}$ to better estimate resting $\mathrm{CT}$.

\section{Methods}

\section{Study Design}

This investigation used a conventional validation approach to the development and validation of a new sigmoid equation for ECTemp $^{\mathrm{TM}}$. The present investigation aimed to improve resting CT estimation by retraining a new sigmoid equation for EC$\mathrm{Temp}^{\mathrm{TM}}$ on an updated development dataset. The original development dataset was from an investigation (Tharion et al., 2013) that evaluated the use of a physiological status monitoring system by soldiers during considerable thermal-work strain in the field. The updated development dataset combines the original development dataset (Tharion et al., 2013) with resting CT data from half of the volunteers randomly selected from a supplementary dataset (Welles et al., 2018). The remaining volunteers from the supplementary dataset were used in the model validation dataset. We took this approach to fit a new sigmoid equation that would correct lower CT estimates while producing higher CT estimates that are nearly identical to the original quadratic equation. All volunteers were briefed on the procedures, benefits, and risks of the study and gave their informed consent prior to data collection. The investigators adhered to the policies for protection of human subjects as prescribed in Army Regulation 70-25. All research was conducted under the oversight of Institutional Review Boards.

\section{Model Development}

The updated model development dataset included data from 25 volunteers (age, $23 \pm 3$ yrs; height, $1.72 \pm 0.07 \mathrm{~m}$; body mass, 68.5 $\pm 8.1 \mathrm{~kg}$ ). The sample included three women (age, $24 \pm 4 \mathrm{yrs}$; height, $1.70 \pm 0.02 \mathrm{~m}$; body mass, $63.3 \pm 7.3 \mathrm{~kg}$ ) and $11 \mathrm{men}$ (age, $22 \pm 2$ yrs; height, $1.75 \pm 0.07 \mathrm{~m}$; body mass, $70.9 \pm 7.9 \mathrm{~kg})$. The sample included the 17 male U.S. Army soldiers (age, $23 \pm 4$ yrs; height, $1.79 \pm 0.08 \mathrm{~m}$; body mass, $81.3 \pm 10.8 \mathrm{~kg}$ ) from the original development dataset (Tharion et al., 2013). Heart rate (Equivital EQ02, Hidalgo Cambridge, UK) and CT (Jonah Thermometer Pill, Respironics, Bend, OR) data were collected during a summer field training exercise at Fort Bragg, North Carolina (air temperature, $24-36^{\circ} \mathrm{C}$; relative humidity $(\mathrm{RH}), 42-97 \%$; wind speed, $0-4 \mathrm{~ms}^{-1}$ ). The field exercise included periods of sleep, rest, foot movement, and vigorous upper body work resulting in a wide range of CT $\left(36-40^{\circ} \mathrm{C}\right)$.

The eight volunteers from the supplementary dataset (Welles et al., 2018) that were randomly assigned to the model development dataset (age, $22 \pm 3$ yrs; height, $1.74 \pm 0.07 \mathrm{~m}$; body mass, $68.8 \pm 9.1 \mathrm{~kg}$ ) included three women (age, $24 \pm 4 \mathrm{yrs}$; height, $1.70 \pm 0.02 \mathrm{~m}$; body mass, $63.3 \pm 7.3 \mathrm{~kg}$ ) and five men (age, $21 \pm$ 1 yrs; height, $1.76 \pm 0.08 \mathrm{~m}$; body mass, $72.2 \pm 8.4 \mathrm{~kg}$ ). Heart rate (Equivital EQ02, Hidalgo Cambridge, UK) and CT (Jonah 
Thermometer Pill, Respironics, Bend, OR) data were collected over two calorimeter chamber visits. Each volunteer ingested a thermometer pill approximately $2 \mathrm{hr}$ before data collection began. Calorimeter chamber temperature was set to each volunteer's preferences between $18-22^{\circ} \mathrm{C}$ during pre-trial equipment fitting and was regulated within $\pm 2{ }^{\circ} \mathrm{C}$. Volunteers entered into the calorimeter chamber at approximately $1700 \mathrm{hr}$ and were restricted to sleep or sedentary tasks (e.g., computer work, watching television) until $\sim 0930 \mathrm{hr}$ the following day. Volunteers were allowed to consume water ad libitum but food intake was restricted to a standardized dinner $(1800 \mathrm{hr})$ and breakfast (0700 hr).

\section{Model Validation}

The eight volunteers from the supplementary dataset (Welles et al., 2018) that were randomly assigned to the model validation dataset (age, $24 \pm 3$ yrs; height, $1.71 \pm 0.07 \mathrm{~m}$; body mass, 68.2 $\pm 7.1 \mathrm{~kg}$ ) included 2 women (age, $24 \pm 4$ yrs; height, $1.62 \pm 0.03 \mathrm{~m}$; body mass, $63.4 \pm 3.2 \mathrm{~kg}$ ) and 6 men (age, $24 \pm 3 \mathrm{yrs}$; height, $1.74 \pm$ $0.06 \mathrm{~m}$; body mass, $69.8 \pm 7.3 \mathrm{~kg}$ ). HR and CT data were collected from these volunteers over two calorimeter chamber visits. Each volunteer ingested a thermometer pill approximately $2 \mathrm{hr}$ before data collection began. Calorimeter chamber temperature was set to each volunteer's preferences between $18-22^{\circ} \mathrm{C}$ during pre-trial equipment fitting and was regulated within $\pm 2{ }^{\circ} \mathrm{C}$. Volunteers entered into the calorimeter chamber at approximately $1700 \mathrm{hr}$ and were restricted to sleep or sedentary tasks (e.g., computer work, watching television) until $\sim 0930 \mathrm{hr}$ the following day. Volunteers were allowed to consume water ad libitum but food intake was restricted to a standardized dinner (1800 hr) and breakfast $(0700 \mathrm{hr})$.

\section{ECTemp $^{\text {TM }}$ Algorithm}

The ECTemp ${ }^{\text {TM }}$ algorithm is based upon an extended Kalman filter (Welch \& Bishop, 1995) that is comprised of a time update and observation model. The original development and validation study (Buller et al., 2013) contains a detailed description of how each model coefficient was derived. The time update model relates how CT changes minute-to-minute and the uncertainty associated with this change. The observation model relates an observation of HR to CT as well as the uncertainty of this mapping. The initial CT observed was used to initialize ECTemp ${ }^{\text {TM }}$ for all experiments conducted in this investigation. Subsequently, the following six equations are applied iteratively after each minute time point $(t)$ to provide a new estimate of $C T_{\mathrm{t}}$ and its associated variance $\left(v_{t}\right)$ given a current $\mathrm{HR}$ observation $\left(H R_{t}\right)$ as well as the previous CT estimate $\left(C T_{t-1}\right)$ and previous variance $\left(v_{t-1}\right)$.

(1) Compute a CT preliminary estimate $\left(\widehat{C} T_{t}\right)$ based on the previous CT estimate.

$$
\widehat{C} T_{t}=C T_{t-1}
$$

(2) Compute a preliminary estimate of the variance of the CT estimate $\left(\widehat{v}_{t}\right)$ based on the previous CT variance $\left(v_{t-1}\right)$.

$$
\widehat{v}_{t}=v_{t-1}+0.000484
$$

(3) Compute the extended Kalman filter mapping function variance coefficient $\left(m_{t}\right)$.

$$
m_{t}=-9.1428 \widehat{C} T_{t}+384.4286
$$

(4) Compute the Kalman gain $\left(k_{t}\right)$ weighting factor based on the preliminary estimate of variance and using the extended Kalman filter mapping function variance coefficient $\left(m_{t}\right)$.

$$
k_{t}=\frac{\widehat{v}_{t} m_{t}}{m_{t}^{2} \widehat{v}_{t}+356.4544}
$$

(5) Compute the final CT estimate $\left(C T_{t}\right)$ using the preliminary time-update estimate, the error between the $\mathrm{HR}_{\mathrm{t}}$ observation and the expected HR given the preliminary estimate of CT.

$$
\begin{aligned}
C T_{t}= & \widehat{C} T_{t}+k_{t}\left(H R_{t}-\left(-4.5714 \widehat{C} T_{t}^{2}+384.4286 \widehat{C} T_{t}\right.\right. \\
& -7887.1))
\end{aligned}
$$

(6) Compute the variance of the final CT estimate $\left(v_{t}\right)$.

$$
v_{t}=\left(1-k_{t} m_{t}\right) \widehat{v}_{t}
$$

The new sigmoid equation was fit using a generalized logistic function (Richards, 1959). The generalized logistic function used can be written as:

$$
H R_{t}=A+\frac{K-A}{\left(1+Q e^{-B\left(\widehat{C} T_{t}-M\right)}\right)^{1 / v}}
$$

Where $\mathrm{A}=$ lower asymptote, $\mathrm{K}=$ upper asymptote, $\mathrm{Q}=$ is the value when $\widehat{C} T_{t}=\mathrm{M}, \mathrm{B}=$ the growth rate, $\mathrm{M}=$ sets the starting $\widehat{C} T_{t}$ value, and $\mathrm{v}=$ affects the asymptote where maximum growth occurs.

\section{Statistical Analyses}

All statistical analyses were performed using RStudio (Version 0.98.1056, RStudio, Inc., Boston, MA). Data are displayed as mean \pm standard deviation (SD). All CT data were visually inspected to identify outliers and artifact associated with fluid ingestion. The goal of this investigation was to update Equations 3 and 5. The sigmoid model was fit using a generalized logistic function to minimize the squared error using the iterative techniques previously described in the original development study (Buller et al., 2013). Bias was computed as the mean of the differences between the estimated CT and observed CT. 95\% limits of agreement (95\% LoA) were computed as bias $\pm 1.96 \cdot \mathrm{SD}$.

\section{Results}

Figure 1 displays HR plotted on CT and the line of best fit for the quadratic model from the original investigation data and the new sigmoid model learned from the development data from the current study. The optimal equation for the sigmoid model was determined to be the following:

$$
H R_{t}=41+\frac{152}{\left(1+0.06 e^{-0.89\left(\widehat{C} T_{t}-37.84\right)}\right)^{1 / 0.07}}
$$

The sigmoid equation was incorporated into the original algorithm by replacing Equations 3 and 5 with Equations 8 and 9 respectively. 

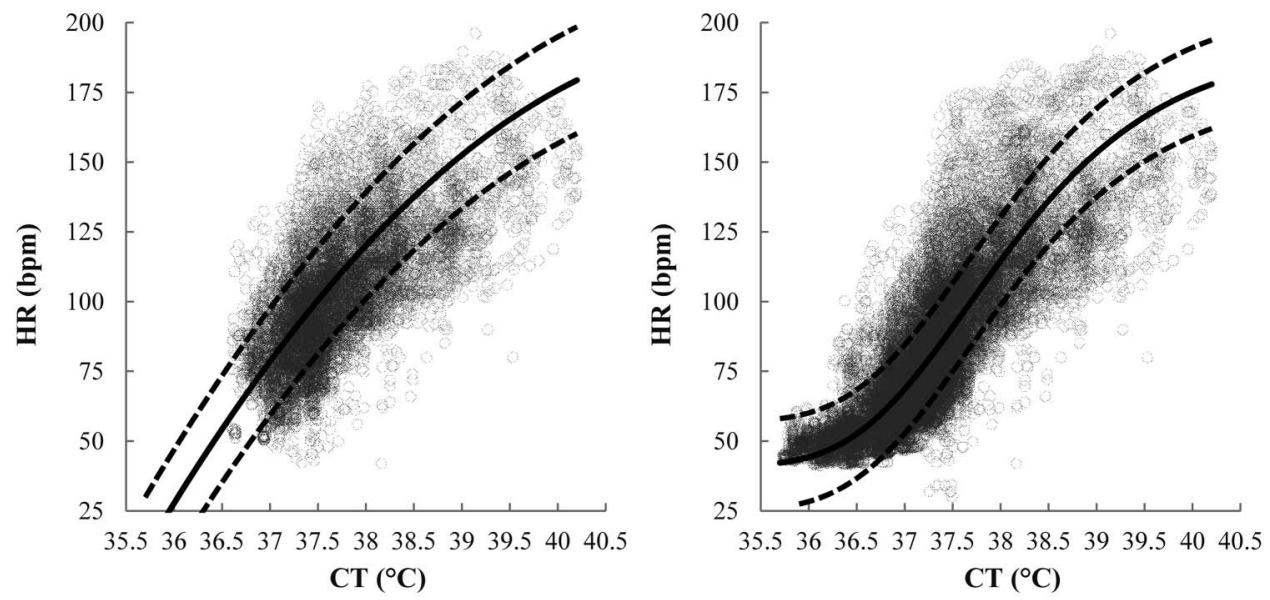

Figure 1 - Heart rate (HR) plotted on observed core temperature (CT) from the original development dataset (left panel) and updated model development dataset (right panel). Solid line, trend line for mean HR; Dotted lines, $M \pm S D$.
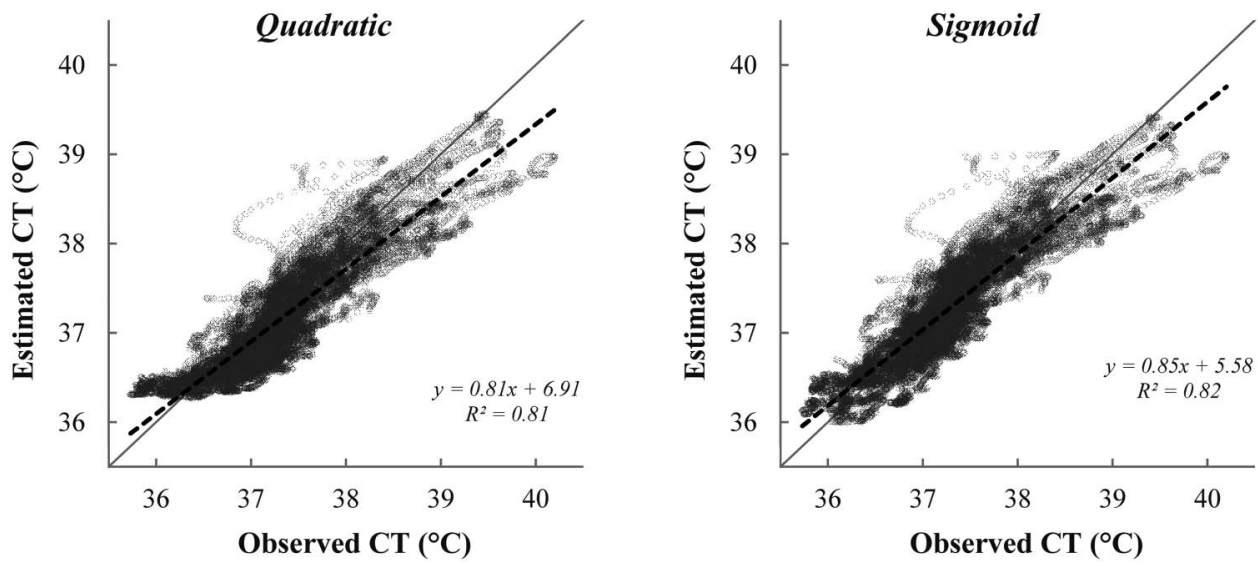

Figure 2 - Estimated core temperature (CT) plotted on observed CT from the development data for the quadratic and sigmoid models with linear trendline (dashed).

$$
\begin{aligned}
m_{t}=\frac{\left(8.1168 e^{-0.89(C T-37.84)}\right)\left(0.06 e^{-0.89(C T-37.84)}+1\right)^{-15.2857}}{0.07} \\
C T_{t}=\widehat{C} T_{t}+k_{t}\left(H R_{t}\right. \\
\left.\quad-\left(41+\frac{152}{\left(1+0.06 e^{-0.89\left(\widehat{C} T_{t}-37.84\right)}\right)^{1 / 0.07}}\right)\right)
\end{aligned}
$$

model $\left(0.29^{\circ} \mathrm{C}\right)$. Figure 5 displays Bland-Altman plots from the validation data for the quadratic and sigmoid models. Both the bias and $95 \%$ LoA were higher for the quadratic model (bias, $-0.22 \pm$ $\left.0.30^{\circ} \mathrm{C} ; 95 \% \mathrm{LoA},\left[-0.81^{\circ} \mathrm{C}, 0.37^{\circ} \mathrm{C}\right]\right)$ compared to the sigmoid model (bias, $-0.13 \pm 0.26^{\circ} \mathrm{C} ; 95 \% \mathrm{LoA},\left[-0.64^{\circ} \mathrm{C}, 0.38^{\circ} \mathrm{C}\right]$ ).

\section{Discussion}

This investigation demonstrates that the ECTemp ${ }^{\mathrm{TM}}$ algorithm closely estimates resting CT. The sigmoid model was superior to the quadratic model in each metric analyzed and is consequently preferable for both resting and active CT estimation. The new sigmoid ECTemp $^{\text {TM }}$ is a viable alternative to direct resting CT measurement. Future research needs to evaluate ECTemp $^{\text {TM, }}$ s circadian rhythm estimation applications.

While this investigation demonstrated the superior accuracy of the new ECTemp ${ }^{\mathrm{TM}}$ model, the sigmoid function is also advantageous since features, such as the range of HR values, can be more easily adjusted than the quadratic function. This added flexibility would allow for individualization of the ECTemp ${ }^{\mathrm{TM}}$ model to a person's resting and maximal heart rates similar to the Karvonen 

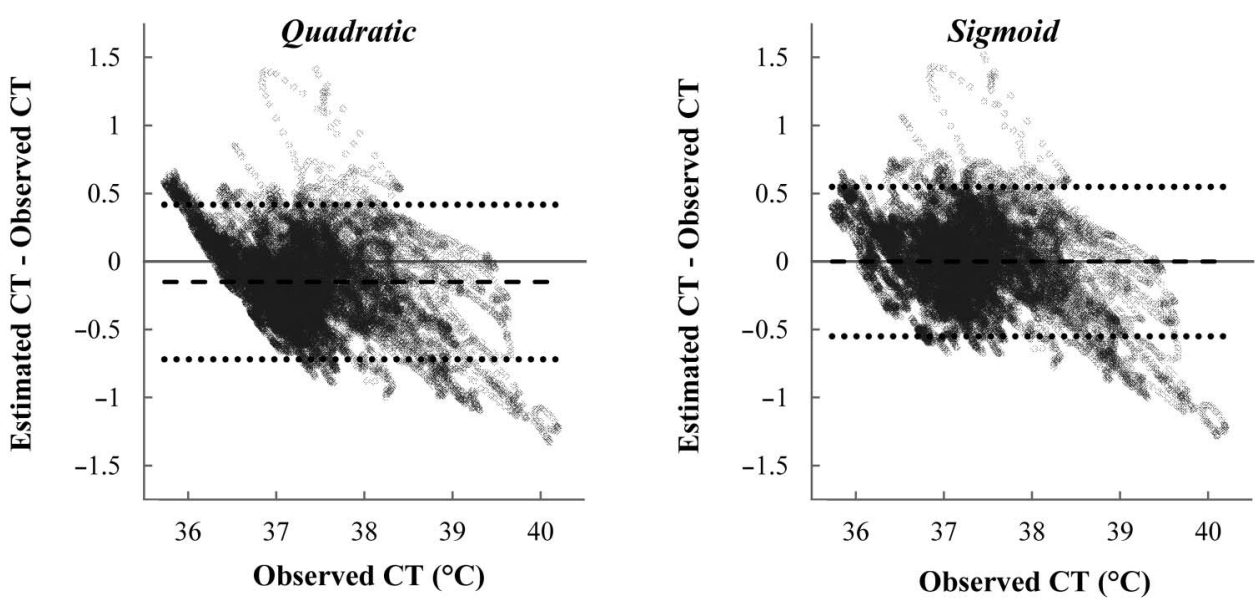

Figure 3 - Bland-Altman plot of agreement between estimated and observed core temperature (CT) from the development data for the quadratic and sigmoid models with bias (dashed line) and lower and upper 95\% limits of agreement (dotted lines).
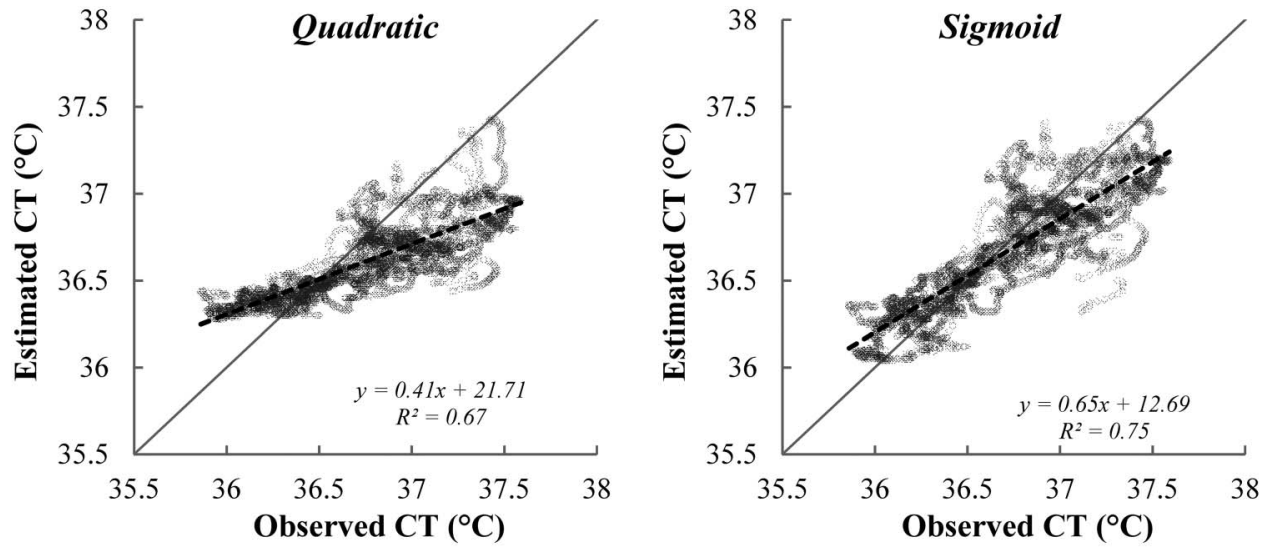

Figure 4 - Estimated core temperature (CT) plotted on observed CT from the validation data for the quadratic and sigmoid models with linear trendline (dashed).
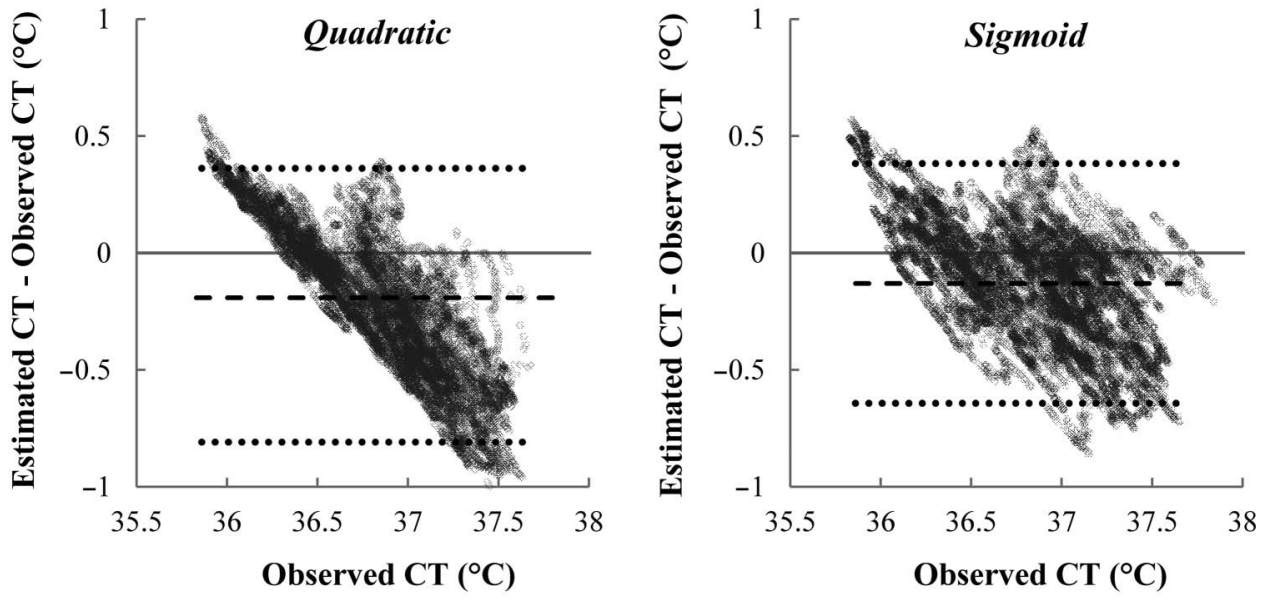

Figure 5 - Bland-Altman plot of agreement between estimated and observed core temperature (CT) from the development data for the quadratic and sigmoid models with bias (dashed line) and lower and upper 95\% limits of agreement (dotted lines). 
formula (Karvonen \& Vuorimaa, 1988). Consequently, the individualization of the ECTemp ${ }^{\mathrm{TM}}$ model is a topic of interest for future research.

ECTemp $^{\text {TM }}$ could not be evaluated as a circadian rhythm estimator in this study due to several limitations. Data was only collected over 12- to 16-hr segments of the day with no data recorded between $0930-1730 \mathrm{hr}$. Additionally, some of the initial CT data was lost due to water consumption artifacts (Wilkinson, Carter, Richmond, Blacker, \& Rayson, 2008). Masking effects such as the sleep-wake cycle and dietary intake (Rietveld, Minors, \& Waterhouse, 1993) were not controlled during data collection. However, these issues will likely arise during circadian rhythm monitoring in free-living conditions. Ultimately, further research is required to validate ECTemp ${ }^{\mathrm{TM}}$ as a circadian rhythm estimator.

Our study has several other limitations. Estimation errors may have been induced by stimuli with different effects on HR and CT such as activity, ambient light exposure, and sleep (Gubin et al., 2017). There were also only eight volunteers in the validation group. As such, it is difficult to uncover any latent variables related to individual characteristics that may have resulted in greater estimation errors. However, each of these volunteers did attend two separate test visits. ECTemp ${ }^{\mathrm{TM}}$ needs to be validated in populations other than healthy active young men and women.

\section{Conclusion}

ECTemp $^{\mathrm{TM}}$ is a validated HR-based resting CT estimation algorithm. The new sigmoid equation corrects lower CT estimates while producing nearly identical estimates to the original quadratic equation at higher CT. The demonstrated accuracy of ECTemp ${ }^{\mathrm{TM}}$ encourages future research to explore the algorithm's potential as a non-invasive means of tracking CT circadian rhythms.

\section{Acknowledgments}

The views expressed in this paper are those of the authors and do not reflect the official policy of the Department of Army, Department of Defense, or the US Government. This research was supported in part by appointments to the Postgraduate Research Participation Program at the U.S. Army Medical Research Institute of Environmental Medicine administered by the Oak Ridge Institute for Science and Education through an interagency agreement between the U.S. Department of Energy and USAMRMC.

\section{References}

Bouchama, A., \& Knochel, J.P. (2002). Heat stroke. The New England Journal of Medicine, 346(25), 1978-1988. PubMed ID: 12075060 doi:10.1056/NEJMra011089

Buller, M.J., Tharion, W.J., Cheuvront, S.N., Montain, S.J., Kenefick, R.W., Castellani, J., . . Hoyt, R.W. (2013). Estimation of human core temperature from sequential heart rate observations. Physiological Measurement, 34(7), 781-798. PubMed ID: 23780514 doi:10. 1088/0967-3334/34/7/781

Buller, M.J., Tharion, W.J., Duhamel, C.M., \& Yokota, M. (2015). Realtime core body temperature estimation from heart rate for first responders wearing different levels of personal protective equipment. Ergonomics, 58(11), 1830-1841. PubMed ID: 25967760 doi:10. 1080/00140139.2015.1036792

Gagge, A.P., Stolwijk, J., \& Hardy, J. (1967). Comfort and thermal sensations and associated physiological responses at various ambient temperatures. Environmental Research, 1(1), 1-20. PubMed ID: 5614624 doi:10.1016/0013-9351(67)90002-3

Gubin, D., Weinert, D., Rybina, S., Danilova, L., Solovieva, S., Durov, A., ... Ushakov, P. (2017). Activity, sleep and ambient light have a different impact on circadian blood pressure, heart rate and body temperature rhythms. Chronobiology International, 34(5), 632-649. PubMed ID: 28276854 doi:10.1080/07420528.2017.1288632

Hunt, A.P., Bach, A.J., Borg, D.N., Costello, J.T., \& Stewart, I.B. (2017). The systematic bias of ingestible core temperature sensors requires a correction by linear regression. Frontiers in Physiology, 8, 260. PubMed ID: 28496414 doi:10.3389/fphys.2017.00260

Jagannath, A., Peirson, S.N., \& Foster, R.G. (2013). Sleep and circadian rhythm disruption in neuropsychiatric illness. Current Opinion in Neurology, 23(5), 888-894. doi:10.1016/j.conb.2013.03.008

Karvonen, J., \& Vuorimaa, T. (1988). Heart rate and exercise intensity during sports activities. Practical application. Sports Medicine, 5(5), 303-312. PubMed ID: 3387734 doi:10.2165/00007256-198805050-00002

Looney, D.P., Buller, M.J., Welles, A.P., Leger, J.L., Stevens, M., Gribok, A., ... Hoyt, R.W. (2017). Accuracy of the estimated core temperature (ECTemp) algorithm in estimating circadian rhythm indicators (Report No. No.T17-08; AD1031877). Natick, MA: U.S. Army Research Institute of Environmental Medicine.

Montain, S.J., Sawka, M.N., Cadarette, B.S., Quigley, M.D., \& McKay, J.M. (1994). Physiological tolerance to uncompensable heat stress: Effects of exercise intensity, protective clothing, and climate. Journal of Applied Physiology, 77(1), 216-222. PubMed ID: 7961236 doi:10. 1152/jappl.1994.77.1.216

Niedermann, R., Wyss, E., Annaheim, S., Psikuta, A., Davey, S., \& Rossi, R.M. (2014). Prediction of human core body temperature using non-invasive measurement methods. International Journal of Biometeorology, 58(1), 7-15. PubMed ID: 23760405 doi:10.1007/ s00484-013-0687-2

O'Brien, C., Hoyt, R.W., Buller, M.J., Castellani, J.W., \& Young, A.J. (1998). Telemetry pill measurement of core temperature in humans during active heating and cooling. Medicine \& Science in Sports \& Exercise, 30(3), 468-472. doi:10.1097/00005768-199803000-00020

Poole, S., \& Stephenson, J. (1977). Core temperature: Some shortcomings of rectal temperature measurements. Physiology \& Behavior, 18(2), 203-205. PubMed ID: 866456 doi:10.1016/0031-9384(77)90122-6

Potter, A.W., Blanchard, L.A., Friedl, K.E., Cadarette, B.S., \& Hoyt, R.W. (2017). Mathematical prediction of core body temperature from environment, activity, and clothing: The heat strain decision aid (HSDA). Journal of Thermal Biology, 64, 78-85. PubMed ID: 28166950 doi:10.1016/j.jtherbio.2017.01.003

Refinetti, R., Lissen, G.C., \& Halberg, F. (2007). Procedures for numerical analysis of circadian rhythms. Biological Rhythm Research, 38(4), 275-325. PubMed ID: 23710111 doi:10.1080/09291010600903692

Richards, F. (1959). A flexible growth function for empirical use. Journal of Experimental Botany, 10(2), 290-301. doi:10.1093/jxb/10.2.290

Richmond, V.L., Davey, S., Griggs, K., \& Havenith, G. (2015). Prediction of core body temperature from multiple variables. Annals of Occupational Hygiene, 59(9), 1168-1178. PubMed ID: 26268995 doi:10. 1093/annhyg/mev054

Rietveld, W.J., Minors, D.S., \& Waterhouse, J.M. (1993). Circadian rhythms and masking: An overview. Chronobiology International, 10(4), 306312. PubMed ID: 8403074 doi:10.1080/07420529309059713

Savvidis, C., \& Koutsilieris, M. (2012). Circadian rhythm disruption in cancer biology. Molecular Medicine, 18, 1249-1260. PubMed ID: 22811066 doi:10.2119/molmed.2012.00077

Sawka, M.N., Latzka, W.A., Montain, S.J., Cadarette, B.S., Kolka, M.A., Kenneth, K.K., 2nd, \& Gonzalez, R.R. (2001). Physiologic tolerance to uncompensable heat: Intermittent exercise, field vs. laboratory. 
Medicine \& Science in Sports \& Exercise, 33(3), 422-430. PubMed ID: 11252069 doi:10.1097/00005768-200103000-00014

Shi, S.Q., Ansari, T.S., McGuinness, O.P., Wasserman, D.H., \& Johnson, C.H. (2013). Circadian disruption leads to insulin resistance and obesity. Current Biology, 23(5), 372-381. PubMed ID: 23434278 doi:10.1016/j.cub.2013.01.048

Sim, S.Y., Joo, K.M., Kim, H.B., Jang, S.J., Kim, B.O., Hong, S.B., ... Park, K.S. (2016). Estimation of circadian body temperature rhythm based on heart rate in healthy, ambulatory subjects. IEEE Journal of Biomedical and Health Informatics, 21(2), 407-415. PubMed ID: 26915140 doi:10.1109/JBHI.2016.2529655

Tharion, W.J., Buller, M.J., Potter, A.W., Karis, A.J., Goetz, V., \& Hoyt, R.W. (2013). Acceptability and usability of an ambulatory health monitoring system for use by military personnel. IIE Transactions on
Occupational Ergonomics and Human Factors, 1, 203-214. doi:10. 1080/21577323.2013.838195

Welch, G., \& Bishop, G. (1995). An introduction to the kalman filter (TR 95-041). Chapel Hill, NC: University of North Carolina.

Welles, A.P., Buller, M.J., Looney, D.P., Rumpler, W.V., Gribok, A.V., \& Hoyt, R.W. (2018). Estimation of metabolic energy expenditure from core temperature using a human thermoregulatory model. Journal of Thermal Biology, 72, 44-52. PubMed ID: 29496014 doi:10.1016/ j.jtherbio.2017.12.007

Wilkinson, D.M., Carter, J.M., Richmond, V.L., Blacker, S.D., \& Rayson, M.P. (2008). The effect of cool water ingestion on gastrointestinal pill temperature. Medicine \& Science in Sports \& Exercise, 40(3), 523528. PubMed ID: 18379216 doi:10.1249/MSS.0b013e31815cc43e 


\section{Erratum: Looney et al. (2018)}

In the original publication of this article, an author's affiliation was printed incorrectly. The affiliation for Looney, Buller, Potter, Tharion, Welles, Friedl, and Hoyt was listed as US Army Institute of Environmental Medicine, and should have been listed as U.S. Army Research Institute of Environmental Medicine. The online version of this article has been corrected. We apologize for this error. 